\title{
Public good and private good valuation for waiting time reduction: a laboratory study
}

\author{
Tibor Neugebauer • Stefan Traub
}

Received: 19 January 2010 / Accepted: 8 March 2011 / Published online: 23 March 2011

(C) Springer-Verlag 2011

\begin{abstract}
In a laboratory experiment, subjects were endowed with money and waiting time. Preferences for waiting time reduction were elicited with salient rewards both as a private good and as a public good. The allocations of the public good that were theoretically predicted by the Nash equilibrium and the Lindahl equilibrium, respectively, were computed from the individual private good valuations and compared with the subjects' actual contributions. We found a significant positive correlation between private good valuations in terms of willingness-to-pay and public good valuations in terms of voluntary contributions. Group contributions to public waiting time reduction significantly exceeded the non-cooperative prediction and were close to the socially optimal level. However, for a majority of subjects, the Lindahl equilibrium was not able to predict the observed contributions.
\end{abstract}

\section{Introduction}

A standard assumption in economics is that individuals maximize their well-being regardless of other people's preferences. The necessary condition for utility maximization implies that individual marginal benefits equal individual marginal costs. This condition equally applies to private goods as well as public goods in the noncooperative Nash equilibrium. Consequently, the private provision of public goods leads to underprovision and efficiency losses in comparison to the social optimum.

T. Neugebauer

Faculté de Droit, d'Économie et de Finance, Université de Luxembourg,

1240 Luxembourg, Luxembourg

S. Traub $(\bowtie)$

Department of Economics and ZeS, University of Bremen, 28359 Bremen, Germany

e-mail: traub@uni-bremen.de 
The social optimum is characterized by the well-known Samuelson (1954) condition, according to which the sum of individual marginal benefits must equal marginal costs. However, Samuelson (1954, p. 388) conjectured it would be impossible to implement this condition by voluntary private contributions as described by the Lindahl equilibrium (1919); in the absence of the possibility to exclude economic agents from the consumption of the public good, the non-cooperative Nash equilibrium allocation would be the more likely outcome of private provision.

In this article, we investigate with laboratory data the question whether private public goods provision is inefficient. More specifically, we test whether the Nash equilibrium can account for the observed behavior better than the Lindahl solution, as supposed by Samuelson (1954). We also check whether the valuation of private goods in terms of willingness-to-pay (WTP) and the valuation of public goods in terms of voluntary contributions correlate. A high correlation between both measures would indicate that people essentially orient their contributions to the public good toward the individual consumption value of the private good. Hence, private good valuations could be used as proxies for public good valuations. On the other hand, a low correlation would indicate that revealed public good preferences are mainly governed by other motives like free-riding incentives, social preferences, etc.

The economic experiment that we designed for this purpose involves the reduction of waiting time as the good to be valued in a within-subjects setting. First, subjects reveal their preferences for private waiting time reduction in a second-price auction. Then, they decide on a voluntary contribution toward public waiting time reduction in a public goods game. Both tasks involve salient rewards. We use the revealed private good preferences (WTP) to predict the Nash and the Lindahl equilibrium contributions, respectively, and compare them to their actual contributions to public waiting time reduction. Our results contradict Samuelson (1954) conjecture, since the observed level of public waiting time reduction is close to the predicted group optimum. It significantly exceeds the Nash equilibrium prediction. However, for a majority of subjects the Lindahl equilibrium is not able to predict the observed contributions. Moreover, we find a significant positive correlation between private good and public good valuations, but with the qualification that the correlation is distinctly lower than one. Hence, the private good valuation of waiting time reduction is only an imperfect indicator of public good valuation.

In recent years, a considerable body of literature on other regarding preferences has emerged that allows for such differences in the valuation of public and private goods, for example, the contributions on reciprocity (see Fehr and Schmidt 2003; Sobel 2005, for literature surveys), on impure altruism and the "warm glow of giving" (Andreoni 1990), and on errors in decision making (see Andreoni 1995; Anderson et al. 1998). Although the issue taken up in this article, whether public and private goods are substitutes, has not really been explored so far, it has been questioned. For instance, List and Shogren (1998) highlighted that "future research should explore whether private goods can serve as reasonable proxies for public preferences" (p. 203). Shogren (2006), who surveyed the literature on public good valuation, did not cite any study that directly tries to contrast non-hypothetical valuations for public and private goods. As the sole author, Bohm (1972) experimentally studied the issue in his seminal paper on experimental public good valuation, yet 
on the basis of hypothetical questions. ${ }^{1}$ Thus, our laboratory study seems to fill a gap. That such a gap should exist is astonishing in the light of a huge body of literature on public good valuations having been created during the last decades.

Due to missing market data, most of the empirical public good valuations today are based on the contingent valuation method. One of the major critique points against this approach (Hausman 1993) has been that this method relies on replies to hypothetical questions. Economists generally doubt that people truthfully state their preferences when nothing is at stake (for a recent discussion, see Camerer and Hogarth 1999). Another important approach to empirical public goods valuations has involved hedonic pricing (Palmquist and Smith 2002, survey the literature) which can only indirectly elicit preferences by making use of market data.

An important alternative to empirical research is laboratory research, which allows direct and non-hypothetical elicitation of preferences by making use of salient rewards. A significant laboratory institution for the valuation of public goods is the Smith Auction (Smith 1980). In Smith's experiments, subjects formed collectives of size 3, 6, or 9. Previously, they had been assigned to three different parameter classes involving different money endowments and payoff functions. The classes were evenly distributed within the groups. Subjects submitted a 2-tuple sealed bid consisting of a maximal contribution and a quantity proposal to the provision of a public good. The mean proposed quantity was computed and produced if the sum of contributions weakly exceeded its production costs. If more contributions were raised than needed, a proportional rebate rule applied. Smith reported that his "experimental results support a slight over-provision of public goods relative to the Lindahl optimum. However, individual bids do not support Lindahl optimal bids..." (p. 598). Much of the more recent experimental work on public goods has focused on the voluntary contribution mechanism (VCM) (Isaac et al. 1984), which is a symmetric linear game in which subjects decide on a contribution toward a public good only. ${ }^{2}$ In the standard VCM, the Nash equilibrium implies zero contributions, and the Lindahl equilibrium allocation implies contribution of the entire endowment (see Hey 1991; Davis and Holt 1993; Ledyard 1995; Keser 2002, for literature surveys). Observed contributions in the oneshot game spread from zero to the full endowment averaging between 40 and $60 \%$ of the group optimum. The Smith Auction and VCM directly elicit preferences for public goods only; they induce the relative valuation for private goods. Moreover, all goods in these experimental institutions are represented by monetary payoffs. In contrast to these approaches, our study involves a tradeoff between private monetary payoffs and a real public good, namely, waiting time reduction. Our design therefore is a rather accurate implementation of Samuelson (1954) pure theory of public expenditure.

Compared to other goods that have been valued in the field and in the laboratory (Harrison and List 2004; Shogren 2006), waiting time reduction can be implemented in the laboratory very inexpensively. Beyond being cheap for the experimenter in

\footnotetext{
1 Bohm (1972) referred that, regardless of the share subjects had to pay of their stated willingness to pay for a public good, they would always report the same amount. The issue of private good valuation was addressed in one hypothetical question in which the offered good was supplied at zero costs.

2 However, more recent experimental research also involves non-linear payoff functions (for example, Nalbantian and Schotter 1997; see Laury and Holt 2008, for a literature survey).
} 
monetary terms, waiting time has an important dimension in the supply of services and goods, public ones as well as private ones. Most goods and services are not instantaneously available as their allocation causes waiting time for the demander. Waiting time can affect the life, the health, and the welfare of citizens. A public institution such as the army, police, fire brigade, public health system, ${ }^{3}$ or public jurisdictional system $^{4}$ must be prepared to effectively serve the citizen in need in a reasonable amount of time. ${ }^{5}$ In the private sector, waiting time for customers is crucial for a firm's success as it affects its turnover and the satisfaction of its customers. ${ }^{6}$ For its importance in an economy, waiting time can be viewed at least from two different angles: from the individual's (the micro-) perspective, waiting time is a private bad; from the society's (the macro-) perspective, waiting time is a public bad. Conversely, the reduction of waiting time for demanded services and commodities is a good as it increases welfare.

So far, only a small number of laboratory experiments in the literature involved decisions about waiting time. Hartman (2007) estimated from a road congestion experiment that his student subjects had average valuations of (waiting) time of between $\$ 10$ and $\$ 18$ per hour. In an experimental investigation of time preferences, Kroll and Vogt (2008) found that waiting time was perceived as a loss and that subjects behaved risk seeking with respect to risky waiting time decisions. Kroll and Vogt (2009) studied the St. Petersburg Paradox in an experimental setup, where subjects were endowed with waiting time instead of money.

The article is organized as follows. In the next section, we introduce the experimental design. Thereafter, in Sect. 2.5, we discuss the theoretical benchmarks of social optimum and Nash equilibrium. In the third section, the experimental results are reported and Sect. 4 concludes.

\section{The experimental design}

We report the results of four hand-run, two-part experimental sessions conducted at the University of Hannover, Germany. In each part, subjects were endowed with $€ 15$ and $1 \mathrm{~h}$ of waiting time. The two parts were separated by a week. Subjects earned an average of $€ 25.59$ ( $€ 1 \simeq \$ 1.30$ ). We elicited the individual demand for waiting time

\footnotetext{
3 Waiting times for health care are a significant issue in many countries. Governments provide huge funding for a reduction, and patients with high waiting costs choose private treatment. Much research has been dedicated to estimating the induced welfare loss (Cullis et al. 2000, survey the literature).

4 Vereeck and Mühl (2000, p. 243) report data from Belgium where "court delay has proven to be a serious political problem of national importance... The situation is particularly dramatic though improving in the Courts of Appeal, where the average court delay in the last decade was over 6 years."

5 The effectiveness of any service institution to managing clients' waiting time depends on the quantity and quality of its workforce, on its subsidiary locations, and on production capacities (for example, beds in public hospitals).

6 This issue is of general importance. Waiting for food, transport, or for the referee reports from a submission to an academic journal are just some examples for the impact of waiting time on utility. Private waiting time plays a particularly important role for drug addicts (Kirby and Petry 2004).
} 
reduction as a private good by means of a second price sealed bid auction (first part) and as a public good in the second part. ${ }^{7}$

\subsection{Eliciting private good valuations}

Value elicitation by second-price auctions is the standard approach in experimental research on non-induced values (Shogren 2006). The second price sealed bid auction (of the first part) involved simultaneous multiple-unit bidding. Each subject $i$ had to submit a bid $b_{i}^{t}$ for each of four possible waiting time reductions of $t=60,45,30$, and $15 \mathrm{~min}$, knowing that she could acquire only one reduction. Bids were required to be weakly decreasing and were restrained to the interval of $€[0.00 ; 15.00]$. Submission of bids indicating Eurocents rather than only Euros was strongly encouraged (see the Instructions in the Appendix A). Once the bids were collected, 60 min waiting time reduction were assigned to the high bidder at the second highest bid. In case of a tie, the winner was determined by chance among the high bidders. The winners' bids for all subsequent auctions were canceled. Following the same procedure, 45, $30 \mathrm{~min}$ and finally $15 \mathrm{~min}$ of waiting time reduction were assigned to the high bidder among the remaining subjects. All other subjects were assigned no waiting time reduction.

As subjects might have perceived the four different waiting time reductions as (imperfect) substitutes, which would imply downward-biased bids, we also computed corrected bids $\tilde{b}_{i}^{t}$ for each subject according to the formula $\tilde{b}_{i}^{t}=b_{i}^{t} /[(N-K+1) /(N-$ $\left.k^{t}+1\right)$ ], where $N$ denotes the number of subjects attending the auction, $K=4$ is the number of auctioned waiting time reductions, and $\left(k^{60}=1\right), \ldots,\left(k^{15}=4\right)$, the respective auction stage (see, for example, Neugebauer 2004). We performed all computations and statistical test reported in Sect. 3 with benefit function estimated both, from the original and the corrected bids. Since there were no qualitative differences between them, we decided to report only the output resting upon the original data. ${ }^{8}$ Furthermore, we have to acknowledge the well-documented tendency for overbidding in second-price auctions. While the "substitution bias" may have led to a lower WTP, overbidding may have led to a higher WTP as compared to the unknown true valuations. At the best, both biases canceled out each other, which is a further reason for us to rely on the original data.

\subsection{Eliciting public good valuations}

The public goods game (of the second part) was one shot and subjects were matched randomly (by manual draws from a hat) to groups of four. In case the number of participants in a session was not a multiple of 4 , the remaining subjects formed a group, randomly completed by subjects from other groups, in order to determine their payoffs. In the public goods game, the hour of waiting time was assigned to a group,

\footnotetext{
7 Note that all subjects first took part in the auction and then participated in the public good experiment. In order to minimize potential order effects and to accustom subjects to the object of the study, waiting was practised by all subjects before the first part of the experiment started (see below).

8 The output for the corrected data is available from the authors on request.
} 
and not to an individual as in the auction. Every subject was asked to privately make a contribution of $€ c_{i}^{\text {act }}, c_{i}^{\text {act }} \in[0.00,15.00]$, to the reduction in group waiting time. Two limiting cases were possible: If a group collected $€ 0.00(€ 30.00)$ for the reduction in group waiting time, every group member had to wait 60 (0) min. If the group collected more than $€ 30$, the surplus was proportionally rebated (Smith 1980). ${ }^{9}$ Thus, a subject's contribution was $30 c_{i}^{\text {act }} / \sum c_{j}^{\text {act }}$ if $\sum c_{j}^{\text {act }}>30$ and $c_{i}^{\text {act }}$ otherwise. ${ }^{10}$

Regarding group waiting time reduction, we considered two treatments: In the first treatment, the marginal cost of a minute in group waiting time reduction was held constant at $€ 0.5$. In the second treatment, the marginal cost of the $t$ th minute in waiting time reduction was $€ t / 61, t \in[0,60]\left(1 / 61 \times \sum_{t=1}^{60} t=30\right)$. Seconds were averaged out; e.g., a group would be allocated a waiting time reduction of $24 \mathrm{~min}$ and $12 \mathrm{~s}$ for $€ 5$. We refer to the first treatment as the constant marginal costs treatment (ConstMC) and to the second as the increasing marginal costs treatment (IncrMC) in the following.

As to the linear "production" of the public good, the ConstMC treatment resembles the standard VCM, which alleviates comparison of the results. Furthermore, due to its linearity the relationship between individual contribution and group waiting time reduction is easily conceived by the subjects. The ConstMC treatment, however, has the disadvantage that for subjects with non-decreasing marginal utility of waiting time reduction, there exists no Lindahl equilibrium (see below). Hence, we decided to design a second treatment, which due to the more complicated cost structure requires more computational effort of our subjects, but is immune to the problem of non-decreasing marginal utility.

Costs of waiting time reduction were presented to subjects in a table indicating, in discrete steps of $1 \mathrm{~min}$, reduction in waiting time, remaining waiting time and expenses (see Appendix B). In both parts, subjects were accompanied to a lecture hall after their waiting time reduction had been determined. There they were seated at numbered places and were asked to wait silently under supervision until the experimenter would indicate the end of the waiting time. While waiting they were not allowed to read, talk, sleep, drink, eat or pursue any other activity whatsoever.

In order to prepare subjects for the task and to help them to price the time accurately, waiting was practiced during the instructional session of the first part for $5 \mathrm{~min}$ before any decision was taken. The first and the second part were scheduled at the same time on the same weekday, the second part being 1 week later. By enrolling for one session, subjects committed to participate in both parts. At the beginning of the first part, each subject received an identification number indicating the seats to be taken during the experiment. Instructions (see Appendix A) were read aloud, possible questions were answered, record sheets were filled in and results were calculated. After the second part they were paid privately.

\footnotetext{
9 A proportional rebate rule was also applied by Isaac et al. (1989) (but only in case contributions fell short of a threshold). For alternative rebate rules in public goods experiments see Marks and Croson (1998).

10 In the experiment, no group's contribution exceeded the threshold level of $€ 30$ : the maximum was $€ 27$. Hence, the rebate rule did not have to be applied. Apart from that, Marks and Croson (1998) showed that introducing a proportional rebate rule does not change the efficient group outcome.
} 


\subsection{Benefit functions}

Let $y$ denote subjects $i$ s initial endowment (that is, the $€ 15$ given to her at the beginning of the experiment) and $b_{i}^{t}$ her true valuation of a $t$ minutes' waiting time reduction, that is, the benefit of being allowed to leave the waiting room earlier than after $60 \mathrm{~min}$ measured in monetary terms. $b_{i}^{t}$ is the WTP for a quantity change in waiting time reduction (from zero to $t$ ). It can be expressed by means of a money-metric indirect utility function $\mu_{i}(t \mid 0, y)$, where $\mu_{i}$ is the amount of income required to keep the subject on the same level of utility as in $(0, y)$ if waiting time reduction is changed from zero to $t: b_{i}^{t}=\mu_{i}(0 \mid 0, y)-\mu_{i}(t \mid 0, y)$ with $\mu_{i}(0 \mid 0, y) \equiv y$ (see Randall and Stoll 1980). As explained above, in the experiment, $b_{i}^{t}$ was assessed for four values of $t: 15,30,45$, and $60 \mathrm{~min}$.

The unknown "true" benefit function is estimated using a second-order Taylor approximation under the assumption that the benefit from a zero minutes' waiting time reduction is zero, that is, $b_{i}^{0}=0$. Given these five points, we estimate

$$
b_{i}^{t}=\alpha_{i} t+\beta_{i} t^{2}+\varepsilon_{i}
$$

for every subject, where $\varepsilon_{i}$ denotes an error term. The subject's estimated benefit function and marginal benefit function are then given by

$$
\widehat{b_{i}(t)}=\hat{\alpha}_{i} t+\hat{\beta}_{i} t^{2}
$$

and

$$
\widehat{m b_{i}(t)}=\hat{\alpha}_{i}+2 \hat{\beta}_{i} t
$$

respectively.

More elaborate alternatives to the quadratic equation (2) are conceivable, ${ }^{11}$ yet it exhibits several advantages for our purpose. First, setting the quadratic term equal to zero would be equivalent to the assumption that there is no income effect. In this case, the coefficient $\hat{\alpha}$ could simply be interpreted as the ratio of constant marginal utility of the good and marginal utility of income (Morey and Greer Rossmann 2003, p. 3), transforming minutes of waiting time reduction into monetary units. Hence, for every subject, we can test on income effects by estimating (1) and checking for significance of $\hat{\beta}$. Second, both concave and convex shapes of the benefit function are possible. Third, having estimated (1), it is relatively easy to calculate closed-form solutions for the individual and social optima. Note that we require subjects to be weakly nonsaturated in waiting time reduction over the full range $t \in[0,60]$, that is, we impose the ex ante restrictions $\hat{\alpha}_{i} \geq 0$ and $\hat{\alpha}_{i}+120 \hat{\beta}_{i} \geq 0$ on our subjects' preferences. ${ }^{12}$

\footnotetext{
11 For a theoretical treatment of deriving closed-form solutions for compensating variations with price and quantity changes see Morey and Greer Rossmann (2003). See also the references stated therein, in particular Johnson and Desvousges (1997).

12 Initially, 18 subjects violated either condition. Re-estimating equation (1) with the ex ante restriction $\beta_{i}=0$, i.e., linearizing the benefit function, resulted in $\hat{\alpha}_{i}>0$ and an adequate fit for all of these cases. Hence, none of these subjects had to be excluded from the analysis.
} 


\subsection{Payoff functions}

Let $c_{i}$ denote subject $i$ s actual contribution to public waiting time reduction, where the sum of contributions equals the production cost of the public good: $C=\sum_{i} c_{i}$. In the ConstMC treatment, the money equivalent payoff function of a subject is as follows:

$$
\pi_{i}=15-c_{i}+\hat{\alpha}_{i} \times 2 \sum_{j} c_{j}+\hat{\beta}_{i} \times\left(2 \sum_{j} c_{j}\right)^{2}
$$

The equation allows us to highlight the differences between our design and the standard linear VCM. Here, the marginal return of the public good is $2 \times\left(\hat{\alpha}_{i}+2 \hat{\beta}_{i} \sum_{j} c_{j}\right)$. In contrast to the present design, in the standard VCM the valuation of the public good is ex ante restricted to be linear and does not depend on the size of the public good $\left(\hat{\beta}_{i}=0 \forall i\right),{ }^{13}$ and the parameter $\hat{\alpha}_{i}=\alpha \forall i$ is induced by the experimenter rather than elicited as in the first part of our experiment. In the standard VCM, the public good would thus yield a marginal return of $2 \times \alpha$, which is usually called the marginal per capita return (Isaac et al. 1984), and the income effect would be neglected.

Analogously, in the IncrMC treatment the payoff function is given by

$$
\pi_{i}=15-c_{i}+\hat{\alpha}_{i} \times\left(120 \sum_{j} c_{j}\right)^{0.5}+\hat{\beta}_{i} \times 120 \sum_{j} c_{j} .
$$

Accordingly, the marginal return of the public good is given by $\sqrt{30} \hat{\alpha}_{i}\left(\sum_{j} c_{j}\right)^{-0.5}+$ $120 \hat{\beta}_{i}$. It depends on the size of the public good even if there is no income effect: the marginal return unambiguously drops as the public good becomes relatively more expensive (the sum of contributions increases). Note that in the ConstMC treatment this effect could be positive (for positive $\hat{\beta})$, zero $(\hat{\beta}=0)$, or negative $(\hat{\beta}<0)$.

\subsection{Theoretical benchmarks}

Using the above stated payoff functions it is straightforward to calculate the respective theoretical "predictions" for the subjects' contribution to the public good according to the Samuelson condition, in the Lindahl equilibrium, and in the Nash equilibrium, respectively. Since the computations are lengthly and involve many different special cases, we omit the details and give only an intuitive description here. ${ }^{14}$ Note that we deal with both the Lindahl equilibrium and the Nash equilibrium in a purely normative sense. The experiment did neither involve a social planner who sets individualized marginal prices in such a way that every subject in the group has an incentive to demand

\footnotetext{
13 Laury and Holt (2008) survey the literature on nonlinear VCMs. For example, Andreoni (1993) used the logarithms of the private and the public good, respectively, in the payoff function.

14 The formulae are available from the authors on request.
} 
his or her efficient quantity of waiting time reduction in terms of the Lindahl solution. Nor did the subjects know the distributions of the other subjects' preference parameters or even their exact values. Hence, we cannot guarantee that the Nash equilibrium or the Lindahl equilibrium are the right descriptive models of subjects' behavior even if our test procedure detects compliance between our data and one of the predictions. Rather, by theoretical prediction we mean that we estimate for each of our subjects the Nash and Lindahl equilibria as if they have had the necessary information on the other subjects' preferences.

The efficient solution corresponding to the Samuelson condition is computed by adding the payoff functions of the four group members and solving the first derivative with respect to $C$ for $C^{\text {opt }}$. Plugging the result back into the individual benefit function yields the Lindahl contribution $c_{i}^{\text {opt }}$. However, for the quadruple $\left\{c_{i}^{\mathrm{opt}}: i=1, \ldots, 4\right\}$ to be an equilibrium also the second-order condition for an individual net-benefit (excess of benefit over contribution) maximum has to be satisfied for each group member. To be able to evaluate the theory, we have to exclude from the individual analysis the data of those subjects whose net-benefit functions are inconsistent with the concave shape assumption. Since about half of the subjects participating in the ConstMC treatment exhibited convex marginal net-benefit, the Lindahl solution was only computed for the IncrMC treatment, where this problem did not occur due to the convexity of the cost function.

In the ConstMC treatment, for the ease of computations, we set the experimental marginal costs parameter relatively high (0.5) to ensure that individual marginal benefits would never exceed marginal costs. Hence, in the Nash equilibrium no subject was willing to contribute. In the IncrMC treatment, we made use of the fact that no subject exhibited estimated marginal benefits high enough to spend her entire endowment on waiting time reduction. The maximum number of minutes a subject could afford would be 42.43 , given an initial endowment of $€ 15$. The 43rd minute would involve marginal costs of $€ 0.71$. This amount is much higher than the highest marginal evaluation of waiting time reduction by any subject, which was $€ 0.35$. Hence, in each group only one subject — the one exhibiting the highest marginal benefits-will make a positive contribution in the Nash equilibrium. For all other group members contributions should be zero.

\section{Results}

Our analysis rests on a sample of 87 subjects, 44 of which participated in the ConstMC treatment and 43 of which were assigned to the IncrMC treatment. ${ }^{15}$ The data analysis involves both between-subjects and within-subjects comparison based on the responses recorded in the first and the second part of the experiment.

\footnotetext{
15 Actually, 95 subjects participated in the first part. Seven subjects did not show up in the second part, one subject had to be disqualified for leaving the experiment without waiting.
} 
Table 1 Results of group analysis

\begin{tabular}{|c|c|c|c|c|}
\hline & \multicolumn{2}{|l|}{ Median } & \multicolumn{2}{|c|}{ Confidence intervals for $C$} \\
\hline & $C$ Euros & $t(\min )$ & $95 \%$ & $99 \%$ \\
\hline \multicolumn{5}{|l|}{ ConstMC treatment } \\
\hline (i) Actual & 12.08 & 24 & {$[8.54,15.58]$} & {$[7.31,16.63]$} \\
\hline (ii) Optimal & 0.00 & 0 & {$[0.00,10.32]$} & {$[0.00,15.97]$} \\
\hline (iii) Nash & 0.00 & 0 & 0.00 & 0.00 \\
\hline \multicolumn{5}{|l|}{ Tests } \\
\hline (iv) Actual-optimal & 6.10 & 12.20 & {$[-0.86,11.65]$} & {$[-4.42,13.28]$} \\
\hline (v) Actual-Nash & $12.08^{* *}$ & 24 & {$[8.54,15.58]$} & {$[7.31,16.63]$} \\
\hline \multicolumn{5}{|l|}{ IncrMC treatment } \\
\hline (i) Actual & 13.46 & 40 & {$[9.62,17.22]$} & {$[8.36,18.33]$} \\
\hline (ii) Optimal & 7.13 & 29 & {$[5.02,9.81]$} & {$[4.43,10.88]$} \\
\hline (iii) Nash & 1.84 & 14 & {$[1.40,1.88]$} & {$[1.06,1.88]$} \\
\hline \multicolumn{5}{|l|}{ Tests } \\
\hline (iv) Actual-optimal & $4.62^{*}$ & 8 & {$[0.54,8.50]$} & {$[-0.29,9.69]$} \\
\hline (v) Actual-Nash & $11.32^{* *}$ & 25 & {$[7.45,15.07]$} & {$[6.05,16.23]$} \\
\hline
\end{tabular}

Note. Confidence intervals for the median based on 10.000 random samples of 11 (10) groups each. Tests are two-tailed $(* p \leq 0.05, * * p \leq 0.01) ; \mathcal{H}_{0}$ : the medians are equal

3.1 Are Lindahl and Nash equilibrium predictions good descriptions of observed group behavior?

In Table 1, we report the results of the group analysis for both treatments, ConstMC and IncrMC. The table lists the medians of (i) the actual group contributions and the corresponding waiting time reductions, (ii) the optimum group contributions and waiting time reductions according to the Samuelson condition, and (iii) the Nash equilibrium contributions and waiting time reductions (being always zero for the ConstMC treatment). 95 and $99 \%$ confidence intervals for the median are stated at the right side of the table. We used medians rather than means in order to immunize our test results against outliers and non-normality of the underlying distributions. Furthermore, for each treatment, we conducted tests on the equality of (iv) actual and optimum contributions and (v) actual and Nash contributions. The respective test results can also be taken from the table, where one leading asterisk means that a test was significant at the $5 \%$ level and two leading asterisks mean that the test was significant at the $1 \%$ level.

Remember that (i) subjects were randomly matched into groups of four, (ii) anonymity was kept throughout the experiment, and (iii) we used a one-shot design of the group experiment. Since the actual groups that led to the payoffs of subjects were arbitrarily matched, we cannot take it for granted that the resulting group decisions and normative benchmarks are representative for the sample. Hence, confidence intervals and tests were computed using Monte Carlo simulation as follows. In the ConstMC (IncrMC) case, each simulation-run involved the data of 44 (40) subjects. In the former 
case, there were exactly 44 subjects. In the IncrMC case, however, there were 43 subjects. Hence, 40 of the 43 subjects had to be preselected randomly in the first step of the simulation procedure. The 44 (40) subjects were randomly assigned to 11 (10) groups of four subjects in the second step. Then, for each group separately, the actual, optimum, and Nash contributions and waiting time reductions, respectively, and the differences between these quantities were computed. Randomness in the data (measurement error, noise, etc.) was taken into account by adding a normally distributed random variable with zero mean and variance $\sum_{j} \mathrm{SEE}_{j}^{2}$ to the differences, where $\mathrm{SEE}_{j}$ is the standard estimation error of estimating the benefit function (1) for subject $j$. In the fourth step, the median across the eight groups was determined. This fourstep procedure was repeated 10,000 times. ${ }^{16}$ Accordingly, the lower and upper bound of the $95 \%$ (99\%) confidence interval are given by the 250th (50th) smallest and the 250th (50th) largest observation, respectively. ${ }^{17}$

We comment on the ConstMC treatment first. The median of actual group contributions is $€ 12.08$, corresponding to a reduction in waiting time by $24 \mathrm{~min}$. As can be taken from the table, the variation of group contributions is relatively low, ranging between some $€ 7.31$ and $€ 16.63$ according to the $99 \%$ confidence interval. In contrast to this, we get large confidence intervals for the group optima, ranging from zero up to $€ 15.97$, however, with a median of $€ 0$. This reflects the large heterogeneity of individual preferences with regard to waiting time reduction. Note that a median of $€ 0$ means that for more than $50 \%$ of the random samples, the optimum group contribution would have been zero, that is, the sum of marginal benefits did not exceed the marginal costs of 50 Eurocents per minute. As noted in Sect. 2.5, the Nash equilibrium is characterized by zero group contributions.

We cannot reject the null hypothesis that the actual contributions are equal to the optimum contributions, since the $95 \%$ confidence interval contains both negative and positive differences. The median difference of $€ 6.10$ is not significantly different from zero. The equality of actual and Nash contributions, however, is strongly rejected by our data, the difference of $€ 12.08$ being significant at the $1 \%$ level.

For the IncrMC treatment, we observe actual group contributions of $€ 13.46$, corresponding to a waiting time reduction by $40 \mathrm{~min}$. Optimal group contributions amount to $€ 7.13$ Euros $(29 \mathrm{~min})$. Since marginal costs increased from zero to one Euro per minute, the median Nash contribution is larger than zero (€1.84 or $14 \mathrm{~min}$ ). In contrast to the ConstMC treatment, testing on the equality of actual and optimum contributions does now reject the null hypothesis that actual contributions are equal to the optimum contributions, though only at the $5 \%$ level.

It might appear worthwhile to study the welfare implications of our subjects' contribution behavior. The ConstMC is less suitable for this undertaking as the median optimum and Nash contributions did not differ from zero for most groups. Hence, we concentrate on the IncrMC treatment. We compare median group welfare in the social optimum, in the Nash equilibrium, and according to actual group contributions with one another by computing their respective ratios. Welfare is computed as the sum of the

\footnotetext{
16 Neglecting the first step, the number of possible permutations is quite large: $44 ! /\left(11\right.$ ! $\left.4 !^{11}\right)=4.4 \times 10^{31}$.

17 In simulating a large number of group compositions, this test procedure allows for the fact that in our non-induced values framework subjects did not know their group members' preferences.
} 
group members' monetary payoff functions, where either the optimum, the Nash, or the actual group contribution is plugged into equation (5). In the Nash equilibrium, group welfare reached $97.4 \%$ of the maximum determined by the Samuelson condition. The respective 5 and $1 \%$ confidence intervals for the median are given by $[96.0 ; 98.4]$ and [95.5; 98.6], respectively. Actual group welfare did only slightly but insignificantly exceed the Nash equilibrium (median $100.8 \%$, confidence intervals [98.4; 102.7] and [97.4; 103.4]) and turned out to be significantly lower than the possible maximum (median 98.3\%, confidence intervals [95.9; 99.6] and [95; 99.8]). Hence, because at least $95 \%$ of the (hypothetical) groups overcontributed as compared to the social optimum (see Table 1), a significant welfare loss resulted that was comparable in size to the welfare loss implied by pure Nash behavior.

To summarize, in both treatments subjects contributed significantly more than our first normative benchmark, the Nash equilibrium. In fact, group contributions were higher (in the IncrMC treatment even significantly higher) as our second normative benchmark, the social optimum; that is, higher as in the induced value framework, where subjects contribute about half of the social optimum. In the next subsection, we explore the structure of individual contributions.

\subsection{Are Lindahl and Nash equilibrium predictions good descriptions of observed individual behavior?}

As explained in Sect. 2.5, it is only possible to compute the Lindahl equilibrium when the net-benefit functions are concave. In the ConstMC treatment, this applied only to 19 subjects. Therefore, we decided to conduct the individual analysis only for the IncrMC treatment. Table 2 shows the results of analyzing the individual data gained from the IncrMC treatment. Subject numbers are given in the first column. In columns $2-5$, we state the bids $b_{i}^{t}$ for each subject for waiting time reductions of $t=\{60,45,30,15\} \mathrm{min}$ in the first part of the experiment. The next three columns show subject $i$ s actual contribution $c_{i}^{\text {act }}$, her optimum contribution in the Lindahl equilibrium $c_{i}^{\mathrm{opt}}$, and her contribution according to the Nash solution $c_{i}^{\mathrm{Nash}}$ in the second part of the experiment. The last row contains the respective mean values across subjects.

The procedure of obtaining the optimum bid was as follows: At the outset, one subject was selected. For the remaining 42 subjects, we ascertained all possible permutations of groups of three subjects. There are exactly $42 ! / 3 ! 39 !=11,480$ such permutations. After merging the subject under investigation with each permutation, we calculated for each hypothetical group the optimum waiting time reduction and contribution by accounting for the estimated individual benefit functions. The Lindahl contribution of the subject was then compared to the actual contribution. This procedure was repeated for all 43 subjects. The figure in Table 2 is the median of the 11,480 individually optimal contributions of the respective subject. Analogously, we obtained theoretical predictions for the contribution in the Nash equilibrium.

The tests reported in the last two columns of Table 2 again take into account randomness of the data by adding a normally distributed random variable with mean zero and variance $\mathrm{SEE}_{j}^{2}$ to the respective differences, where $\mathrm{SEE}_{j}$ is the standard estimation 
Table 2 Results of individual analysis: IncrMC treatment

\begin{tabular}{|c|c|c|c|c|c|c|c|c|c|}
\hline \multirow[t]{2}{*}{ No. } & \multicolumn{4}{|l|}{$b_{i}^{t}, t=$} & \multicolumn{3}{|l|}{$c_{i}$} & \multicolumn{2}{|l|}{ Test } \\
\hline & 60 & 45 & 30 & 15 & act & opt & Nash & opt & Nash \\
\hline 1 & 14.00 & 11.00 & 7.00 & 4.00 & 3.44 & 4.15 & 1.81 & -0.72 & $1.95^{* *}$ \\
\hline 2 & 4.00 & 3.00 & 2.00 & 1.00 & 3.00 & 0.90 & 0.00 & $2.10^{* *}$ & $3.00^{* *}$ \\
\hline 3 & 6.00 & 4.00 & 3.00 & 2.00 & 9.75 & 1.38 & 0.00 & $8.34^{* *}$ & $9.71^{* *}$ \\
\hline 4 & 1.14 & 0.86 & 0.57 & 0.28 & 0.00 & 0.23 & 0.00 & $-0.23^{* *}$ & 0.00 \\
\hline 5 & 2.00 & 1.50 & 1.00 & 0.50 & 0.00 & 0.41 & 0.00 & $-0.41^{* *}$ & 0.00 \\
\hline 6 & 7.50 & 5.00 & 2.50 & 0.00 & 0.00 & 2.00 & 0.00 & -2.04 & 0.00 \\
\hline 7 & 15.00 & 10.00 & 7.50 & 5.00 & 5.75 & 4.29 & 1.89 & 1.40 & $4.26^{* *}$ \\
\hline 8 & 12.34 & 12.05 & 7.67 & 3.48 & 9.40 & 3.46 & 2.07 & $6.03^{* *}$ & $7.50^{* *}$ \\
\hline 9 & 0.04 & 0.03 & 0.02 & 0.01 & 0.90 & 0.01 & 0.00 & $0.89^{* *}$ & $0.90^{* *}$ \\
\hline 10 & 4.00 & 3.00 & 2.00 & 1.00 & 3.00 & 0.90 & 0.00 & $2.10^{* *}$ & $3.00^{* *}$ \\
\hline 11 & 0.00 & 0.00 & 0.00 & 0.00 & 0.00 & 0.00 & 0.00 & 0.00 & 0.00 \\
\hline 12 & 0.00 & 0.00 & 0.00 & 0.00 & 6.00 & 0.00 & 0.00 & $6.00^{* *}$ & $6.00^{* *}$ \\
\hline 13 & 7.61 & 4.15 & 3.17 & 0.00 & 7.50 & 1.93 & 0.00 & $5.47^{*}$ & $7.50^{* *}$ \\
\hline 14 & 10.11 & 8.11 & 5.11 & 0.00 & 1.00 & 3.12 & 0.00 & -2.35 & 0.89 \\
\hline 15 & 6.00 & 3.75 & 2.00 & 1.00 & 0.00 & 1.37 & 0.00 & $-1.38^{* *}$ & -0.00 \\
\hline 16 & 15.00 & 10.00 & 5.00 & 0.00 & 14.80 & 7.38 & 0.00 & 7.38 & $14.78^{* *}$ \\
\hline 17 & 3.50 & 3.00 & 2.50 & 1.00 & 0.90 & 0.82 & 0.00 & -0.10 & $0.88^{* *}$ \\
\hline 18 & 6.00 & 5.00 & 4.00 & 2.00 & 0.25 & 1.44 & 0.00 & $-1.17^{* *}$ & 0.19 \\
\hline 19 & 15.00 & 10.00 & 10.00 & 2.00 & 0.50 & 4.44 & 1.94 & -4.09 & -1.11 \\
\hline 20 & 3.51 & 3.09 & 1.51 & 0.51 & 0.50 & 0.80 & 0.00 & -0.33 & 0.50 \\
\hline 21 & 9.00 & 3.00 & 2.00 & 1.00 & 0.00 & 1.63 & 0.00 & -1.73 & -0.06 \\
\hline 22 & 15.00 & 10.00 & 5.00 & 0.00 & 10.00 & 7.38 & 0.00 & 2.57 & $9.99^{* *}$ \\
\hline 23 & 2.00 & 1.50 & 1.00 & 0.50 & 0.00 & 0.41 & 0.00 & $-0.41^{* *}$ & 0.00 \\
\hline 24 & 15.00 & 11.25 & 7.50 & 3.75 & 3.44 & 4.64 & 1.88 & -1.20 & $1.57^{* *}$ \\
\hline 25 & 15.00 & 11.25 & 7.50 & 3.75 & 6.20 & 4.64 & 1.88 & 1.56 & $4.33^{* *}$ \\
\hline 26 & 14.00 & 10.00 & 7.00 & 2.00 & 9.20 & 4.58 & 0.00 & $4.56^{*}$ & $8.80^{* *}$ \\
\hline 27 & 0.00 & 0.00 & 0.00 & 0.00 & 0.00 & 0.00 & 0.00 & 0.00 & 0.00 \\
\hline 28 & 2.03 & 1.00 & 0.01 & 0.01 & 0.00 & 0.31 & 0.00 & -0.33 & 0.00 \\
\hline 29 & 14.99 & 10.17 & 8.00 & 2.25 & 15.00 & 4.87 & 0.00 & $10.02^{* *}$ & $14.27^{* *}$ \\
\hline 30 & 5.00 & 4.00 & 3.00 & 2.00 & 0.00 & 1.17 & 0.00 & $-1.16^{* *}$ & -0.06 \\
\hline 31 & 3.52 & 3.11 & 2.50 & 1.83 & 1.90 & 0.81 & 0.00 & $1.14^{* *}$ & $1.87^{* *}$ \\
\hline 32 & 4.50 & 3.80 & 2.14 & 0.56 & 0.00 & 1.06 & 0.00 & $-1.08^{*}$ & -0.03 \\
\hline 33 & 3.00 & 3.00 & 0.00 & 0.00 & 0.00 & 0.61 & 0.00 & -0.66 & -0.02 \\
\hline 34 & 5.00 & 5.00 & 5.00 & 0.00 & 7.62 & 1.29 & 0.00 & $6.38^{* *}$ & $* * 7.49$ \\
\hline 35 & 2.51 & 2.50 & 2.40 & 2.00 & 5.00 & 14.42 & 8.75 & $-9.47^{* *}$ & $-3.74^{* *}$ \\
\hline 36 & 12.00 & 8.00 & 6.00 & 5.00 & 0.74 & 3.09 & 0.00 & -2.36 & 0.20 \\
\hline 37 & 10.00 & 8.00 & 7.00 & 5.00 & 12.03 & 2.32 & 1.70 & $9.82^{* *}$ & $11.12^{* *}$ \\
\hline 38 & 2.50 & 2.00 & 1.00 & 0.00 & 2.00 & 0.50 & 0.00 & $1.45^{*}$ & $2.00^{* *}$ \\
\hline 39 & 3.63 & 2.01 & 1.93 & 1.01 & 2.80 & 0.75 & 0.00 & $2.02^{* *}$ & $2.80^{* *}$ \\
\hline
\end{tabular}


Table 2 continued

\begin{tabular}{|c|c|c|c|c|c|c|c|c|c|}
\hline \multirow[t]{2}{*}{ No. } & \multicolumn{4}{|l|}{$b_{i}^{t}, t=$} & \multicolumn{3}{|l|}{$c_{i}$} & \multicolumn{2}{|l|}{ Test } \\
\hline & 60 & 45 & 30 & 15 & act & opt & Nash & opt & Nash \\
\hline 40 & 7.00 & 6.00 & 4.00 & 2.00 & 0.00 & 1.77 & 0.00 & $-1.78^{* *}$ & -0.10 \\
\hline 41 & 10.02 & 8.04 & 6.15 & 3.01 & 3.78 & 2.62 & 0.00 & $1.17^{* *}$ & $3.67^{* *}$ \\
\hline 42 & 9.00 & 7.00 & 6.00 & 5.00 & 0.25 & 2.05 & 0.00 & -1.70 & -0.37 \\
\hline 43 & 15.00 & 13.00 & 12.00 & 9.00 & 0.25 & 5.78 & 2.58 & -5.74 & -2.17 \\
\hline$\mu$ & 7.27 & 5.38 & 3.81 & 1.71 & 3.42 & 2.46 & 0.57 & 0.93 & 2.83 \\
\hline
\end{tabular}

Notes. Median optimum and Nash contributions based on all 11,480 possible group permutations. Tests are two-tailed $(* p \leq 0.05, * * p \leq 0.01)$. $\mathcal{H}_{0}$ : the medians are equal

Table 3 Summary of individual results: IncrMC treatment

\begin{tabular}{lrr}
\hline & $n$ & $\%$ \\
\hline >opt \& >Nash & 15 & 35 \\
$=$ opt \& > Nash & 7 & 16 \\
=opt \& =Nash & 12 & 28 \\
$<$ opt \& =Nash & 8 & 19 \\
$<$ opt \& $<$ Nash & 1 & 2 \\
Sum & 43 & 100 \\
\hline
\end{tabular}

error of estimating the benefit function of subject $j$. The test results are summarized in Table $3.35 \%$ of subjects contributed significantly more than their respective Lindahl contribution. Further $16 \%$ contributed an amount not significantly different from the optimum and more than in the Nash equilibrium. For 12 subjects, we could reject neither the Lindahl nor the Nash equilibrium. These subjects are interpreted as contributing between Nash equilibrium and social optimum, including both. $19 \%$ of subjects contributed the Nash equilibrium benchmark and less than optimal. There was only one subject contributing even less than in the Nash equilibrium.

Summarizing this subsection, the individual analysis (using only the data from the IncrMC treatment) supports the group-level analysis, where group contributions slightly exceeded the optimum contributions according to the Samuelson condition. Here, more than half of the subjects contribute at least as much as their theoretical optimum value and more than according to the Nash equilibrium benchmark. It should be noted, however, that for most subjects (the $95 \%$ interval estimate of) the Lindahl equilibrium failed to predict their individual contributions.

\subsection{Can private goods valuations serve as proxies for public preferences?}

Despite the fact that the voluntary contributions of 24 subjects (see Table 3 ) differ significantly from the Lindahl predictions, we find a significant positive correlation between both quantities: Pearson's correlation coefficient between the subjects' optimal and actual contributions is $\rho=0.452$ ( $p=0.002, N=43)$. On the contrary, the correlation between the actual contributions and the predicted Nash contributions is 
only $\rho=0.13$ ( $p=0.384, N=43$ ). This result suggests that our approach to predict public goods preferences (in terms of the contributions to public waiting time reduction) from revealed private goods preferences (in terms of their WTP) is reasonable for the IncrMC treatment.

For the ConstMC treatment, we cannot compute this correlation coefficient because the estimated WTP functions of many subjects do not exhibit a strictly concave shape (see Sect. 2.5 above). Therefore, we take an alternative approach to testing the hypothesis that private goods valuations can serve as proxies for public goods preferences. Instead of using the WTP functions, we directly compute the correlation of the original bid data from the second-price auction and the voluntary contributions from the public goods game. Pearson's correlation coefficient between the hourly bids and the contributions is $\rho=0.315$ ( $p=0.037, N=44$ ); for the IncrMC treatment, it is $\rho=0.491$ ( $p=0.001, N=43$ ), reassuring us on the prior conclusion for both treatments. ${ }^{18}$

Since the observed correlation is far from being perfect, i.e., $\rho \ll 1$, it is indicated that private good valuations alone do not determine public good valuations. Apart from the standard free-riding incentives, the recent literature on other regarding preferences, such as reciprocity and altruism (see Andreoni 1990; Fehr and Schmidt 2003; Sobel 2005), has offered some clues on additional determinants of public goods preferences.

\section{Conclusion}

We have reported the results of a laboratory study in which subjects were endowed with money and waiting time. Preferences for waiting time reduction were elicited with salient rewards both as a private good by means of a second-price auction and as a public good in the scope of a public goods game. The allocations of group waiting time reduction that were theoretically predicted by the Nash equilibrium and the Lindahl equilibrium, respectively, were computed from the individual private good valuations and compared with the subjects' actual voluntary contributions.

A surprising result of our experiment is that, at the group level, voluntary contributions to public waiting time reduction are in line with or even exceed the social optimum described by the Samuelson condition. This contradicts Samuelson (1954) conjecture that it would be impossible to implement the Lindahl (1919) equilibrium by voluntary contributions due to free-riding incentives. Note that over contribution generated welfare losses comparable in size to Nash behavior. At the individual level, however, the evidence was mixed. For about the same number of individuals observed voluntary contributions fitted either the Lindahl prediction or the Nash prediction better. The result, nevertheless, is in line with earlier experimental results on public goods, which generally show that people do not respond to the free-riding incentives as much as surmised by the theoretical literature (see, e.g., Laury and Holt 2008, for a survey). Our conclusions are in line with Smith (1980) who also confirms the Lindahl

\footnotetext{
18 The significant positive correlation is present also with the other bids for $t=\{45,30,15\}$ in both treatments.
} 
allocation at the group level for the provision of public goods in his experimental study, but at the same time rejects the Lindahl solution as a descriptive model of individual economic behavior (see also Bohm 1972). It should be noted that Samuelson (1954, p. 389) himself concluded that the traditional economics approach to public good valuation might be too simple and that the "sociology" of public goods should be explored in future research.

We have also presented evidence that revealed private good preferences (in terms of WTP for individual waiting time reduction) and public good preferences (in terms of voluntary contributions to public waiting time reduction) exhibit a significant positive correlation, but with the qualification that the correlation is distinctly lower than one. Hence, the private good valuation of waiting time reduction is only an imperfect indicator of the public good valuation. We believe that the discrepancy between theory and observed behavior arises from the assumption that people maximize their own benefit regardless of other people's consumption or preferences. An overwhelming number of experimental studies has shown that this assumption is inaccurate in the presence of public goods (Ledyard 1995). Revealed public goods preferences in experiments are heterogeneous and generally indicate a deviation from pure self-interest. Since the Lindahl benchmark based on private good valuations, like the Nash benchmark, disregards other regarding preferences it cannot be a complete descriptive model of voluntary contribution decisions.

Our experimental evidence was obtained in a non-induced value framework, where the public good was waiting time reduction and the private good was money. We believe that our experiment is a rather accurate test of Samuelson (1954) pure theory of public expenditure that complements the extensive literature on public good valuation based on the VCM. As our experimental design, admittedly involved a number of challenges such as the proper elicitation of private good valuations and their conversion into theoretical predictions for the public good valuations, we also hope to stimulate methodological advancements and future research using the non-induced value framework by our study.

Acknowledgments Financial support from the Deutsche Forschungsgemeinschaft under contract TR 458/3-1 is gratefully acknowledged. Sibylle Franz helped us on improving our English writing style. We would like to thank two anonymous referees for their most helpful comments.

\section{Appendix}

\section{A Instructions}

\section{First part}

The experiment will be run on 2 days: today and next week at the same time. To make sure that we will be able to identify you in the next session, you find your personal ID card with a number at your place. Please take it with you and bring it along to the next session. If you participate in both sessions, following the experimental instructions, you will earn a reasonable amount of money. You will be paid the earnings of both 
sessions in private after the second session. Unless you reveal how much you have earned, no-one will get to know.

You receive 15 Euros for participating in today's session. In return you have to wait $1 \mathrm{~h}$ under supervision. During this time, you must be quiet. You are neither allowed to communicate with the other participants nor to do anything else (not even sleeping!). You will be supervised and it will be ensured that you stick to the rules. If you cannot, you will be excluded from the second session and you will not receive any payment. The strict compliance with these conditions is indispensable!

The lecture hall I 301 on the second floor of the building, to which you will be guided shortly, is reserved for the waiting task. Your seat in the waiting room is labeled with your personal ID. You can leave as soon as the supervisor informs you about the end of your waiting time.

There exists a possibility to reduce your personal waiting time by payment. For this purpose, you will take part in four auctions. The offered waiting time reductions are as follows:

1. Auction: $60 \mathrm{~min}$ waiting time reduction (remaining waiting time: $0 \mathrm{~min}$ ).

2. Auction: $45 \mathrm{~min}$ waiting time reduction (remaining waiting time: $15 \mathrm{~min}$ ).

3. Auction: $30 \mathrm{~min}$ waiting time reduction (remaining waiting time: $30 \mathrm{~min}$ ).

4. Auction: $15 \mathrm{~min}$ waiting time reduction (remaining waiting time: $45 \mathrm{~min}$ ).

Note: the order of the bids on your record sheet is reverse!

The auctions proceed according to the following principles:

1. Each participant submits four bids simultaneously and anonymously, which represent the WTP for the waiting time reductions, respectively. The bids must be submitted in Euros on your record sheet WITH indication of the Cents as decimal places behind the dot.

PLEASE USE THIS FORMAT!

2. All bids must be above or at $€ 0.00$, and should not exceed $€ 15$.00! Furthermore, the bids should not decrease from one auction to the next.

3. Once all participants have submitted their bids, the bids for the 1 . auction will be compared. The participant who has submitted the highest bid wins the 1. auction and will be excluded from all remaining auctions. Thereafter, the remaining participants' bids will be compared in the 2 . auction, next those for the 3 . and for the 4. The one with the highest bid, respectively, wins the auction and his or her bids will not be considered in the following auctions.

4. If more than one participant has submitted the highest bid in an auction the winner will be selected (among them) by chance.

5. The auction winner will be charged the highest bid of the remaining participants (his or her own excluded), i.e., it will be taken off the 15 Euro participation fee.

An example: assume the following three bids (ordered by size) are the highest ones submitted in an auction:

$x$ Euros,

$y$ Euros,

$z$ Euros, ...( $x \geq y \geq z)$

The highest bid equals $x$ Euros, the second highest bid equals $y$ Euros, etc. The 
participant who has submitted $x$ Euros wins the auction. The price the participant has to pay equals $y$ Euros.

6. The participant who has won $60 \mathrm{~min}$ of waiting time reduction can leave the waiting room immediately after having entered it. The participant who has won $45 \mathrm{~min}$ of waiting time reduction can leave after waiting $15 \mathrm{~min}$. The auction winners of the 30 and 15 min waiting time reductions can leave after 30 and $45 \mathrm{~min}$, respectively. They will be informed at the end of their waiting time. The participants without waiting time reduction must wait the entire $60 \mathrm{~min}$.

In next week's session, you will receive new instructions for the second part of the experiment in which you can earn another 15 Euros. Please arrive on time, otherwise we cannot ensure your participation. You are going to test now a $5 \mathrm{~min}$ waiting time. The same conditions hold as later, i.e., you are neither allowed to communicate with other participants nor to do anything else. The test will help you with your decision. The test is thought to help to find your decision.

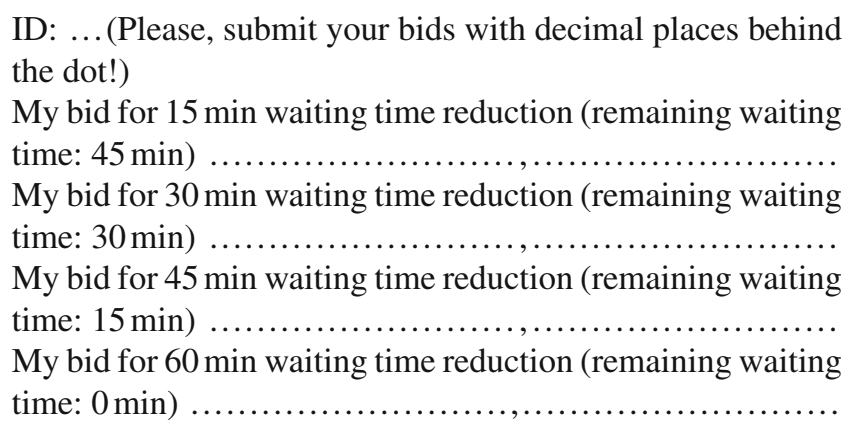

\section{Second part}

In today's session, you are again endowed with 15 Euros. In return you have to wait $1 \mathrm{~h}$ under supervision. During this time, you must be quiet. You are neither allowed to communicate with the other participants nor to do anything else (not even sleeping!). You will be supervised and it will be ensured that you stick to the rules. If you cannot, you will not receive any payment. This includes the money you already earned! The strict compliance with these conditions is indispensable!

The lecture hall I 301 on the second floor of the building, to which you will be guided shortly, is reserved for the waiting task. Your seats in the waiting room are numbered with your personal ID. You can leave as soon as the supervisor informs you about the end of your waiting time.

There exists a possibility to reduce your personal waiting time by payment. You make your decision about waiting time reduction alone. Yet, your decision affects the waiting time of other participants as well. At the same time, your waiting time depends also on the decision of the others. 
You form a group of four participants with three others. The identity of the group members is determined by chance during the experiment, and will not be revealed to you.

All participants decide simultaneously and anonymously how much you want to spend on reduction of the group's waiting time. Please write the amount you want to spend in Euros with Cent as decimal places on your record sheet. PLEASE USE THIS FORMAT, AND DO NOT FORGET TO INCLUDE YOUR PERSONAL ID! The amounts must be at or above $€ 0.00$ and should not exceed $€ 15.00$ !

The sum your group spends on waiting time reduction determines the group's waiting time. You can read the waiting time reduction from the table on the adjoined sheet for all possible amounts the group might spend; every Cent will be taken into account correspondingly.

If your group spends $€ 30$ or more, your waiting time reduction will be $60 \mathrm{~min}$. If your group spends more than $€ 30$, the exceeding amount will be rebated to you proportionally to your expenditure: If your share of the group's expenditure is $x \%$ you will receive a rebate of $x \%$ of the surplus.

The rest of the money you do not spend on waiting time reduction is your personal earning in today's experiment. As soon as every participant has submitted the record sheet the group's waiting time will be calculated. Thereafter, you will be told the result in private.

If your waiting time reduction is $60 \mathrm{~min}$, you can leave the waiting room as soon as you have entered it. If your waiting time reduction is less than $60 \mathrm{~min}$, you will have to wait the time that remains.

As soon as you have been informed about the end of your waiting time, please go to the supervisor to collect your personal receipt. Please fill in your name and sign it! Hand in your receipt at the staff room (room 044) where you will be paid in cash for your earnings from both experimental sessions.

ID:

My expenditure for the group's waiting time reduction is $€$

(Please, submit your amount with the decimal places behind the dot!)

\section{B Cost tables}

\section{ConstMC treatment}

From the table you can read the waiting time reduction on the left, the remaining waiting time and the group's expenditure in Euro on the right, respectively. The sum of your personal expenditure and the ones of the other three group members defines the group's expenditure. If the group's expenditure exceeds $€ 30.00$ the surplus will be rebated proportionally to your expenditure: Given your share of group expenditure is $x \%$ you will receive $x \%$ of the surplus. Your personal expenditure must not exceed $€ 15.00$. 


\begin{tabular}{|c|c|c|c|c|c|}
\hline $\begin{array}{l}\text { Waiting time } \\
\text { reduction } \\
\text { (min) }\end{array}$ & $\begin{array}{l}\text { Remaining } \\
\text { waiting time } \\
\text { (min) }\end{array}$ & $\begin{array}{l}\text { Group's } \\
\text { expenditure }\end{array}$ & $\begin{array}{l}\text { Waiting time } \\
\text { reduction } \\
\text { (min) }\end{array}$ & $\begin{array}{l}\text { Remaining } \\
\text { waiting time } \\
\text { (min) }\end{array}$ & $\begin{array}{l}\text { Group's } \\
\text { expenditure }\end{array}$ \\
\hline 0 & 60 & $€ 0.00$ & 31 & 29 & $€ 15.50$ \\
\hline 1 & 59 & $€ 0.50$ & 32 & 28 & $€ 16.00$ \\
\hline 2 & 58 & $€ 1.00$ & 33 & 27 & $€ 16.50$ \\
\hline 3 & 57 & $€ 1.50$ & 34 & 26 & $€ 17.00$ \\
\hline 4 & 56 & $€ 2.00$ & 35 & 25 & $€ 17.50$ \\
\hline 5 & 55 & $€ 2.50$ & 36 & 24 & $€ 18.00$ \\
\hline 6 & 54 & $€ 3.00$ & 37 & 23 & $€ 18.50$ \\
\hline 7 & 53 & $€ 3.50$ & 38 & 22 & $€ 19.00$ \\
\hline 8 & 52 & $€ 4.00$ & 39 & 21 & $€ 19.50$ \\
\hline 9 & 51 & $€ 4.50$ & 40 & 20 & $€ 20.00$ \\
\hline 10 & 50 & $€ 5.00$ & 41 & 19 & $€ 20.50$ \\
\hline 11 & 49 & $€ 5.50$ & 42 & 18 & $€ 21.00$ \\
\hline 12 & 48 & $€ 6.00$ & 43 & 17 & $€ 21.50$ \\
\hline 13 & 47 & $€ 6.50$ & 44 & 16 & $€ 22.00$ \\
\hline 14 & 46 & $€ 7.00$ & 45 & 15 & $€ 22.50$ \\
\hline 15 & 45 & $€ 7.50$ & 46 & 14 & $€ 23.00$ \\
\hline 16 & 44 & $€ 8.00$ & 47 & 13 & $€ 23.50$ \\
\hline 17 & 43 & $€ 8.50$ & 48 & 12 & $€ 24.00$ \\
\hline 18 & 42 & $€ 9.00$ & 49 & 11 & $€ 24.50$ \\
\hline 19 & 41 & $€ 9.50$ & 50 & 10 & $€ 25.00$ \\
\hline 20 & 40 & $€ 10.00$ & 51 & 9 & $€ 25.50$ \\
\hline 21 & 39 & $€ 10.50$ & 52 & 8 & $€ 26.00$ \\
\hline 22 & 38 & $€ 11.00$ & 53 & 7 & $€ 26.50$ \\
\hline 23 & 37 & $€ 11.50$ & 54 & 6 & $€ 27.00$ \\
\hline 24 & 36 & $€ 12.00$ & 55 & 5 & $€ 27.50$ \\
\hline 25 & 35 & $€ 12.50$ & 56 & 4 & $€ 28.00$ \\
\hline 26 & 34 & $€ 13.00$ & 57 & 3 & $€ 28.50$ \\
\hline 27 & 33 & $€ 13.50$ & 58 & 2 & $€ 29.00$ \\
\hline 28 & 32 & $€ 14.00$ & 59 & 1 & $€ 29.50$ \\
\hline 29 & 31 & $€ 14.50$ & 60 & 0 & $€ 30.00$ \\
\hline 30 & 30 & $€ 15.00$ & 60 & 0 & $>€ 30.00$ \\
\hline
\end{tabular}

\section{IncrMC treatment}

From the table you can read the waiting time reduction on the left, the remaining waiting time and the group's expenditure in Euro on the right, respectively. The sum of your personal expenditure and the ones of the other three group members defines the group's expenditure. If the group's expenditure exceeds $€ 30.00$ the surplus will be rebated proportionally to your expenditure: Given your share of group expenditure is $x \%$ you will receive $x \%$ of the surplus. Your personal expenditure must not exceed $€ 15.00$. 


\begin{tabular}{|c|c|c|c|c|c|}
\hline $\begin{array}{l}\text { Waiting time } \\
\text { reduction } \\
\text { (min) }\end{array}$ & $\begin{array}{l}\text { Remaining } \\
\text { waiting time } \\
\text { (min) }\end{array}$ & $\begin{array}{l}\text { Group's } \\
\text { expenditure }\end{array}$ & $\begin{array}{l}\text { Waiting time } \\
\text { reduction } \\
\text { (min) }\end{array}$ & $\begin{array}{l}\text { Remaining } \\
\text { waiting time } \\
\text { (min) }\end{array}$ & $\begin{array}{l}\text { Group's } \\
\text { expenditure }\end{array}$ \\
\hline 0 & 60 & $€ 0.00$ & 31 & 29 & $€ 8.13$ \\
\hline 1 & 59 & $€ 0.02$ & 32 & 28 & $€ 8.66$ \\
\hline 2 & 58 & $€ 0.05$ & 33 & 27 & $€ 9.20$ \\
\hline 3 & 57 & $€ 0.10$ & 34 & 26 & $€ 9.75$ \\
\hline 4 & 56 & $€ 0.16$ & 35 & 25 & $€ 10.33$ \\
\hline 5 & 55 & $€ 0.25$ & 36 & 24 & $€ 10.92$ \\
\hline 6 & 54 & $€ 0.34$ & 37 & 23 & $€ 11.52$ \\
\hline 7 & 53 & $€ 0.46$ & 38 & 22 & $€ 12.15$ \\
\hline 8 & 52 & $€ 0.59$ & 39 & 21 & $€ 12.79$ \\
\hline 9 & 51 & $€ 0.74$ & 40 & 20 & $€ 13.44$ \\
\hline 10 & 50 & $€ 0.90$ & 41 & 19 & $€ 14.11$ \\
\hline 11 & 49 & $€ 1.08$ & 42 & 18 & $€ 14.80$ \\
\hline 12 & 48 & $€ 1.28$ & 43 & 17 & $€ 15.51$ \\
\hline 13 & 47 & $€ 1.49$ & 44 & 16 & $€ 16.23$ \\
\hline 14 & 46 & $€ 1.72$ & 45 & 15 & $€ 16.97$ \\
\hline 15 & 45 & $€ 1.97$ & 46 & 14 & $€ 17.72$ \\
\hline 16 & 44 & $€ 2.23$ & 47 & 13 & $€ 18.49$ \\
\hline 17 & 43 & $€ 2.51$ & 48 & 12 & $€ 19.28$ \\
\hline 18 & 42 & $€ 2.80$ & 49 & 11 & $€ 20.08$ \\
\hline 19 & 41 & $€ 3.11$ & 50 & 10 & $€ 20.90$ \\
\hline 20 & 40 & $€ 3.44$ & 51 & 9 & $€ 21.74$ \\
\hline 21 & 39 & $€ 3.79$ & 52 & 8 & $€ 22.59$ \\
\hline 22 & 38 & $€ 4.15$ & 53 & 7 & $€ 23.46$ \\
\hline 23 & 37 & $€ 4.52$ & 54 & 6 & $€ 24.34$ \\
\hline 24 & 36 & $€ 4.92$ & 55 & 5 & $€ 25.25$ \\
\hline 25 & 35 & $€ 5.33$ & 56 & 4 & $€ 26.16$ \\
\hline 26 & 34 & $€ 5.75$ & 57 & 3 & $€ 27.10$ \\
\hline 27 & 33 & $€ 6.20$ & 58 & 2 & $€ 28.05$ \\
\hline 28 & 32 & $€ 6.66$ & 59 & 1 & $€ 29.02$ \\
\hline 29 & 31 & $€ 7.13$ & 60 & 0 & $€ 30.00$ \\
\hline 30 & 30 & $€ 7.62$ & 60 & 0 & $>€ 30.00$ \\
\hline
\end{tabular}

\section{References}

Anderson S, Goeree J, Holt C (1998) A theoretical analysis of altruism and decision error in public goods games. J Public Econ 70:297-323

Andreoni J (1990) Impure altruism and donations to public goods: a theory of warm-glow giving. Econ J 100:464-477

Andreoni J (1993) An experimental test of the public goods crowding-out hypothesis. Am Econ Rev 83:1317-1327 
Andreoni J (1995) Cooperation in public goods experiments: kindness or confusion. Am Econ Rev 85:891904

Bohm P (1972) Estimating demand for public goods: an experiment. Eur Econ Rev 3:111-130

Camerer CF, Hogarth RM (1999) The effects of financial incentives in experiments: a review and capitallabor production framework. J Risk Uncertain 19:7-42

Cullis P, Jones JG, Propper C (2000) Waiting and medical treatment: analyses and policies. In: Culyer AJ, Newhouse JP (eds) North Holland Handbook on health economics. Elsevier, Amsterdam pp 12011249

Davis DD, Holt CA (1993) Experimental economics. Princeton University Press, Princeton

Fehr E, Schmidt K (2003) Theories of fairness and reciprocity-evidence and economic applications. In: Dewatripont M, Hansen L, Turnovsky St (eds) Advances in economics and econometrics-8th world congress. Econometric society monographs

Harrison GW, List JA (2004) Field experiments. J Econ Lit 42:1009-1055

Hartman JL (2007) The relevance of heterogeneity in a congested route network with tolls: an analysis of two experiments using actual waiting times and monetized time costs. Dept. of Economics Working Paper, UC Santa Barbara

Hausman JA (ed) (1993) Contingent valuation: a critical assessment. North Holland, New York

Hey JD (1991) Experiments in economics (uncertainty and expectations in economics). Basil Blackwell, Oxford

Isaac RM, Walker J, Thomas S (1984) Divergent evidence on free-riding: an experimental examination of possible explanations. Public Choice 43:113-149

Isaac RM, Schmidtz D, Walker J (1989) The assurance problem in a laboratory market. Public Choice 62:217-236

Johnson F, Desvousges W (1997) Estimating stated preferences with rated-pair data: environmental, health, and employment effects of energy programs. J Environ Plan Manag 34:79-99

Keser C (2002) Cooperation in public goods experiments. In: Bolle F, Lehman-Waffenschmidt M (eds) Surveys in experimental economics-bargaining, cooperation and election stock markets. Physica, Heidelberg pp 71-90

Kirby KN, Petry NM (2004) Heroin and cocaine abusers have higher discount rates for delayed rewards than alcoholics or non-drug-using controls. Addiction 99:461-471

Kroll EB, Vogt B (2008) Loss aversion for time: an experimental investigation of time preferences. FEMM working paper 27, University of Magdeburg

Kroll EB, Vogt B (2009) The St. Petersburg paradox despite risk seeking preferences: an experimental study. FEMM working paper 4, University of Magdeburg

Laury S, Holt C (2008) Voluntary provision of public goods: experimental results with interior nash equilibria. In: Plott C, Smith V (eds) Handbook of experimental economics results. Elsevier, Amsterdam

Ledyard JO (1995) Public goods: a survey of experimental research. In: Kagel J, Roth A (eds) Handbook of experimental economics. Princeton University Press, Princeton

Lindahl E (1919) Just taxation-a positive solution. In: Musgrave RA, Peacock AT (eds) Classics in the theory of public finance. Macmillan, London

List JA, Shogren JF (1998) Calibration of the difference between actual and hypothetical valuations in a field experiment. J Econ Behav Org 37:193-205

Marks M, Croson RT (1998) Alternative rebate rules in the provision of a threshold public good: an experimental investigation. J Public Econ 76:195-220

Morey ER, Greer Rossmann K (2003) Calculating, with varying types of income effects, closed-form solutions for the compensating variation associated with a change in the state of the world. Dept. of Economics Working Paper, University of Colorado at Boulder

Nalbantian HR, Schotter A (1997) Productivity under group incentives: an experimental study. Am Econ Rev 87:314-341

Neugebauer T (2004) Bidding strategies of sequential first price auctions programmed by experienced bidders. Cuadernos Econ 75(3):153-184

Palmquist RB, Smith VK (2002) The use of hedonic property value techniques for policy and litigation. In: Tietenberg T, Folmer H (eds) The international yearbook of environmental and resource economics. Edward Elgar, Cheltenham pp 115-164

Randall A, Stoll JR (1980) Consumer surplus in commodity space. Am Econ Rev 70:449-455

Samuelson PA (1954) The pure theory of public expenditure. Rev Econ Stat 36:387-389 
Shogren JF (2006) Experimental methods and valuation. In: Mäler KG, Vincent J (eds) Handbook of environmental economics, vol 2. North-Holland, Amsterdam pp 969-1027

Smith VL (1980) Experiments with a decentralized mechanism for public good decision. Am Econ Rev 70:584-599

Sobel J (2005) Interdependent preferences and reciprocity. J Econ Lit 43:392-436

Vereeck L, Muhl M (2000) An economic theory of court delay. Eur J Law Econ 10:243-268 